\title{
Simulating Extreme Etesians over the Aegean and Implications for Wind Energy Production in Southeastern Europe ${ }^{\mathscr{O}}$
}

\author{
Stella Dafka, ${ }^{\mathrm{a}}$ Andrea Toreti, ${ }^{\mathrm{b}}$ Juerg Luterbacher,,${ }^{\mathrm{a}, \mathrm{c}}$ Prodromos Zanis, ${ }^{\mathrm{d}}$ \\ EVANGELOS TYRLIS, ${ }^{\mathrm{e}}$ AND ELENA XOPLAKI ${ }^{\mathrm{a}}$

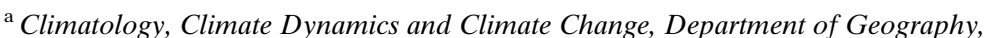 \\ Justus Liebig University Giessen, Giessen, Germany \\ b Joint Research Centre, European Commission, Ispra, Italy \\ ${ }^{\mathrm{c}}$ Centre of International Development and Environmental Research, Justus Liebig University Giessen, Giessen, Germany \\ ${ }^{\mathrm{d}}$ Department of Meteorology and Climatology, School of Geology, Aristotle University of Thessaloniki, Thessaloniki, Greece \\ ${ }^{\mathrm{e}}$ Max Planck Institute for Meteorology, Hamburg, Germany
}

(Manuscript received 21 June 2017, in final form 2 February 2018)

\begin{abstract}
Episodes of extremely strong northerly winds (known as etesians) during boreal summer can cause hazardous conditions over the Aegean Archipelago (Greece) and represent a threat for the safe design, construction, and operation of wind energy turbines. Here, these extremes are characterized by employing a peak-over-threshold approach in the extended summer season (May-September) from 1989 to 2008. Twelve meteorological stations in the Aegean are used, and results are compared with 6-hourly wind speed data from five ERA-Interim-driven regional climate model (RCM) simulations from the European domain of the Coordinated Regional Climate Downscaling Experiment (EURO-CORDEX). The main findings show that, in the range of wind speeds for the maximum power output of the turbine, the most etesian-exposed stations could operate $90 \%$ at a hub height of $80 \mathrm{~m}$. The central and northern Aegean are identified as areas prone to wind hazards, where medium- to high-wind (class II or I according to the International Electrotechnical Committee standards) wind turbines could be more suitable. In the central Aegean, turbines with a cutout wind speed $>25 \mathrm{~m} \mathrm{~s}^{-1}$ are recommended. Overall, RCMs can be considered a valuable tool for investigating wind resources at regional scale. Therefore, this study encourages a broader use of climate models for the assessment of future wind energy potential over the Aegean.
\end{abstract}

\section{Introduction}

The etesians are one of the major and most prominent wind systems in Europe, prevailing over the Aegean Sea during summer and early autumn (Tyrlis and Lelieveld 2013; Anagnostopoulou et al. 2014; Dafka et al. 2016, and references therein). These synoptically driven wind events originate from the combined influence of the high pressure system over central Europe and the Balkans and the extension of the Persian trough over the eastern Mediterranean (Tyrlis and Lelieveld 2013; Dafka et al. 2016). The etesians can reach gale force strength, while they can persist over a period of several days (Dafka et al. 2016).

\footnotetext{
Supplemental information related to this paper is available at the Journals Online website: https://doi.org/10.1175/JAMC-D-170172.s1.
}

Corresponding author: Stella Dafka, styliani.dafka@geogr.unigiessen.de
Thus, the realistic simulation of etesian wind speed, at a particular site, is of major importance for the safe design and construction of wind turbines, as well as for risk assessments for insurance/reinsurance companies.

Several studies have identified central Greece and the Aegean Sea as areas of high potential for wind energy (Bloom et al. 2008; Fyrippis et al. 2010). Borhan (1998) reported that $63 \%$ of the observed pressure gradients during summer months are strong, allowing for wind power potential along the Aegean coasts of Turkey. Fyrippis et al. (2010) estimated high potential wind energy at Naxos (central Aegean) during the period August 2006-July 2007 using Weibull and Rayleigh distribution functions. Bagiorgas et al. (2012) identified maximum mean wind speed of $7.8 \mathrm{~m} \mathrm{~s}^{-1}$ and maximum energy of $20.46 \mathrm{GWh}$ (with $11 \mathrm{yr}$ of available data) in Mykonos (central Aegean). Hueging et al. (2013) and Tobin et al. (2016) pointed to a decrease of energy potential over southern Europe in all seasons for the period 2061-2100, except summer for the Aegean Sea. Despite the economic crisis over the past 
years, Greece experienced a fourfold increase in installed wind energy capacity, reaching $2.82 \mathrm{GW}$ in 2017 (Pineda and Tardieu 2018). In addition, significant investments in the wind energy sector have led to the construction of almost 140 wind farms distributed both in several inland areas and on islands. This energy potential is attracting many investors from all over the world. However, no accurate extreme wind statistics for Aegean measuring stations is available so far.

As a step toward assessing the wind potential over the Aegean Sea, this study aims at evaluating the wind resources and estimating climate models' performance with respect to extreme wind speeds (intense etesians), by analyzing the newest high-resolution Coordinated Regional Climate Downscaling Experiment (EUROCORDEX) regional climate models (RCMs) for Europe (Jacob et al. 2014). Model outputs are validated against daily observational measurements from the Aegean Sea. The EURO-CORDEX simulations are available at

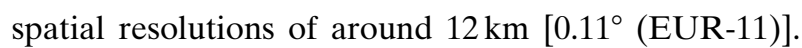
Dafka et al. (2018) evaluated the performance of the EURO-CORDEX RCMs in capturing the etesian wind system for the observational period 1989-2004. They demonstrated the ability of EURO-CORDEX RCMs in simulating the etesians and the associated large-scale atmospheric circulation.

This study analyses the magnitude, frequency, and spatial distribution of extreme winds over the Aegean Sea at three different hub heights, including uncertainty estimates. Further, it identifies key regions that are prone to wind hazards and estimates the return periods for specific extreme events. Overall, it aims at evaluating the state-of-the-art RCMs in reproducing extreme wind speeds over complex terrain in a climatological perspective. Finally, it paves the way for future studies on the use of RCMs in the evaluation of site-specific wind conditions over the Aegean.

The paper is organized as follows: In section 2, instrumental and model data are presented; section 3 provides an explanation of the applied methods; results and discussions are presented in section 4 . The conclusions are given in section 5 .

\section{Data}

Simulations from five models of the EURO-CORDEX ensemble (see Table S1 in the online supplementary material) with different configurations and physical parameterizations are here used. Six-hourly mean sea level pressure (SLP) data as well as zonal and meridional wind components at $10 \mathrm{~m}$ for the months May-September during the EURO-CORDEX hindcast period 1989-2008 have been retrieved. All models, except ARPEGE, version 5.2 (v5.2), are RCMs forced by the ERA-Interim (ERAint; Dee et al. 2011) at their lateral boundaries and by sea surface temperature in the interior of the EUROCORDEX domain. ARPEGE-v5.2 is a global climate model that uses a special regional setup, in which temperature, wind speed, and specific humidity are nudged toward ERAint outside the EURO-CORDEX domain. There is no interior nudging in any of the models used in this study (Prein et al. 2016). Hereinafter, all of the models will be named RCM for sake of brevity and identified by the name of the institution where the simulation was performed. Further details on the models are given in the online supplementary material.

Moreover, 6-h wind speed data (at $10 \mathrm{~m}$ ) from 12 stations over the Aegean Sea (Fig. 1) have been retrieved from the Hellenic National Meteorological Service (see supplemental Table S2). Measurements from this network cover the extended summer season May-September from 1989 to 2008. To compare the RCMs with observations, the simulated wind speed is bilinearly interpolated to the observation sites.

\section{Methods}

A number of studies have applied tools and methods from the extreme value theory to estimate extreme wind events (Patlakas et al. 2016; Kunz et al. 2010; de Oliveira et al. 2011; Della-Marta et al. 2009). To study wind speed extremes associated with etesians, we use the peak-over-threshold approach (POT; Coles 2001; Davison and Smith 1990). The POT approach considers all values greater than a given high enough threshold $u$, and it is based on the Balkema-de HaanPickands theorem (Balkema and de Haan 1974; Pickands 1975). A similar approach has been already used in wind speed modeling (see Vagenas et al. 2017; Kislov and Matveeva 2016; Patlakas et al. 2016; Outten and Esau 2013; Kunz et al. 2010).

\section{a. Selection of the northerlies}

Following Dafka et al. (2016, 2018), we use the pressure gradient over the Aegean Sea to define an etesian day. This methodology considers the daily 6-hourly SLP difference $\Delta P$ between the stations Elliniko (Attica) and Rhodes (eastern Aegean; Fig. 1). However, with respect to observations, a complete daily 6-hourly SLP dataset from the period 1989-2008 is not available. As ERAint realistically reproduces the pressure tendencies in both stations and provides good representation of the etesian wind system (Dafka et al. 2018), the closestto-the-two-stations grid points from ERAint $\left(\Delta P_{\text {ERAint }}\right)$ are here used for the selection of the etesian days in the observational series. In addition, the pressure 


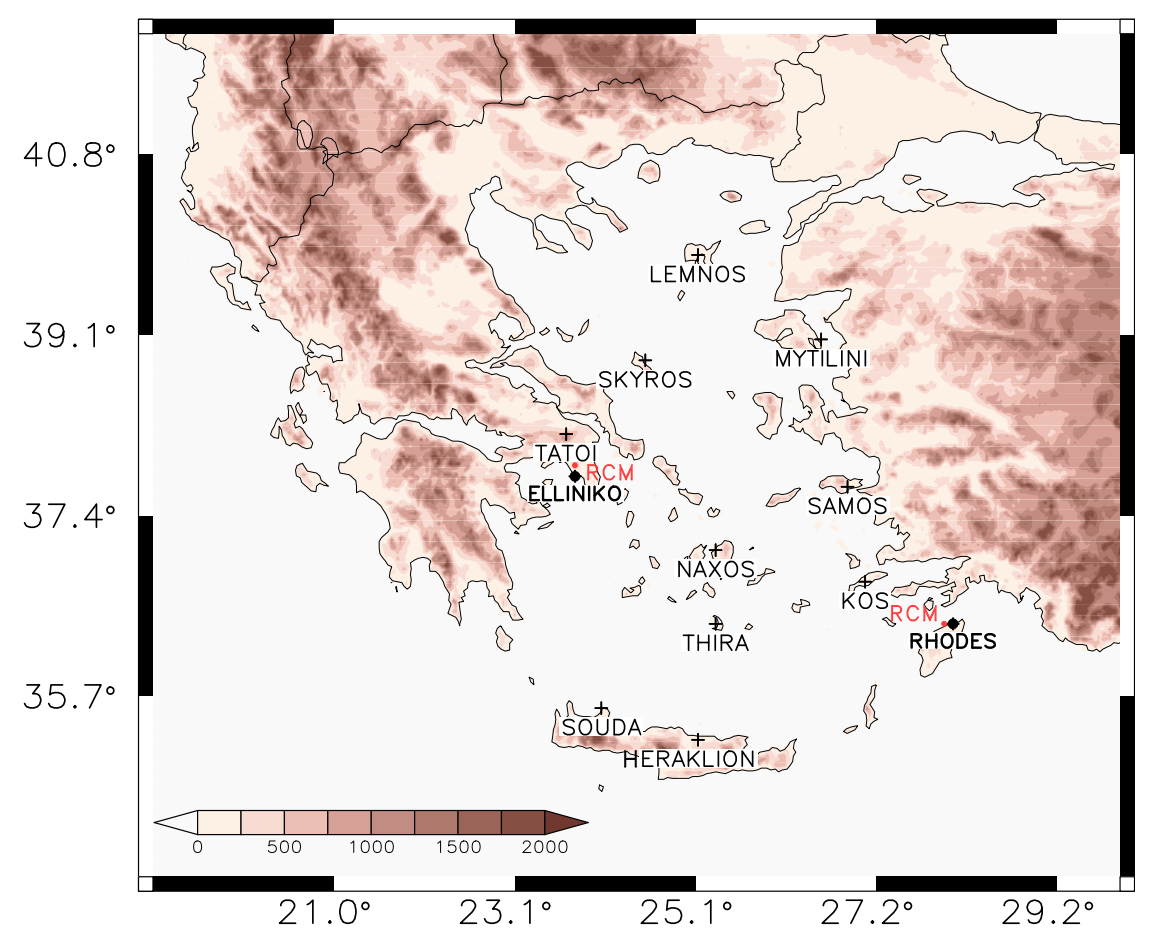

FIG. 1. Study region and location of the 12 Aegean stations (plus signs). The large black dots give the locations of the Elliniko and Rhodes stations. Red dots represent the adjacent grid points of the RCMs. Shading is used to represent the orography of the region (m).

differences of the closest grid points from each $\mathrm{RCM}\left(\Delta P_{\mathrm{CNRM} 1}, \Delta P_{\mathrm{CNRM} 2}, \Delta P_{\mathrm{DMI}}, \Delta P_{\mathrm{SMHI}}\right.$, and $\Delta P_{\mathrm{IPSL}}$; the institutional acronyms in the subscripts are defined in Table S1) to the two stations' grid points are derived. Days with negative $\Delta P$ indicate southerly flow over the Aegean Sea and, thus, are excluded from the analysis.

\section{b. Wind speed interpolation}

In the frame of the Aegean-Gaseous and Aerosol Airborne Measurements (GAME) airborne campaign (Tombrou et al. 2015), three flights were performed to study the meteorological and turbulence parameters over the Aegean Sea during etesians. The planetary boundary layer height was found to have considerable depth, around $1.5 \mathrm{~km}$ over the northern Aegean Sea, while it gradually increased up to $2.5 \mathrm{~km}$ over the southern parts of the Archipelago. During the investigated intense etesians most of the region exhibited neutral to stable atmospheric conditions. Unstable conditions prevailed in the eastern part of Crete during moderate etesians. Newman and Klein (2014) provided new insights about the accuracy of various extrapolation methods of wind speed data for different stability regimes. They showed that the power law produces the most accurate $80-\mathrm{m}$ wind speed estimates for stable regimes. The Monin-Obukhov similarity theory assumes that heat and momentum fluxes are uniform with height (Arya 2001), which is likely not true in case of intense etesians, since they are accompanied by strong wind shear at the surface and strong turbulences fluxes, suggesting the existence of downward transport of momentum toward the surface (Kostopoulos et al. 2013).

The power law (commonly used in wind energy studies; Mölders et al. 2015; Hueging et al. 2013; Ernst and Seume 2012) estimates the wind speed at different heights by using wind speed at a reference height close to the ground (typically $10 \mathrm{~m}$ ). It is defined by

$$
v(z)=v_{\text {ref }}\left(\frac{z}{z_{\text {ref }}}\right)^{p},
$$

where $v(z)$ is the wind speed at height $z, v_{\text {ref }}$ is the wind speed at height $z_{\text {ref }}$, and $p$ is the power-law exponent. High values of $p$ indicate that the wind speed changes rapidly with height, which is common in stable regimes (Newman and Klein 2014). When the wind shear coefficient is properly estimated, the power law can provide a more accurate idea of the renewable energy output of a particular site or area than the log law, which requires neutral stability conditions (Kubik et al. 2011). Indeed, the wind shear exponent varies highly with 
TABLE 1. Classified events of the extended summer season May to September 1989-2008.

\begin{tabular}{clc}
\hline \hline Condition & Name of group & Percentage of events (avg of all datasets) \\
\hline$\Delta P<0$ & Southerly flow & 14.4 \\
$\Delta P \geq 0$ & Northerly flow & 85.6 \\
6-h events with $\Delta P \geq 0$ that satisfy the condition & Intense etesians & 10.0 \\
of wind speed $\geq 90$ th percentile & &
\end{tabular}

height, time of day, season, nature of the terrain, wind speed, and atmospheric stability; thus, its determination at any single location is a complicated task, subject to significant risk of uncertainty (Ray et al. 2006). Emeis (2005) found that for very smooth terrain (offshore and near the coasts) and under nearly neutral conditions the power law is a good approximation of the real surface-layer wind profile, whereas in the periurban coastal areas - over large roughness surfaces - the value of the average exponent is about $0.2(0.14-0.26)$. In addition, Owen (2004) calculated a shear exponent of about 0.17 for nearshore stations in southeast Wisconsin, under moderately stable conditions. More recently, $\mathrm{Ng}$ and Ran (2016) also suggested the value of $\sim 0.17$ for the wind shear exponent in nearshore wind conditions. Rehman et al. (2013) identified a more realistic range of wind shear coefficient between 0.16 and 0.23 for nearshore areas in Saudi Arabia. In this study, the wind speed is extrapolated from the height of $10 \mathrm{~m}\left(z_{\text {ref }}\right)$ to different hub heights $z(50,80$, and $100 \mathrm{~m})$ by employing the power law as described above, with $p=0.2$, consistently with previous studies. Note that the uncertainty in the projected wind speed depends on the uncertainty in the power-law exponents. The standard deviation of the projected speed $\left(\sigma_{v}\right)$ is a measure of the uncertainty and is given by

$$
\sigma_{v}=100 \sigma_{p} \ln \left(\frac{z}{z_{\text {ref }}}\right) \% .
$$

Assuming $p=0.2 \pm 0.05$, the wind speed uncertainty extrapolated from 10 to $80 \mathrm{~m}$ is $\pm 10 \%$.

\section{c. Intense etesians}

For the identification of intense etesians, the 90th percentile of 6-hourly wind speed data (that satisfy the condition $\Delta P \geq 0$ ) is used as threshold. This provides approximately 1000-1400 6-hourly exceedances, representing the top $10 \%$ of wind events at each station. Table 1 gives an overview of the classification method and shows the average percentage of 6-hourly events that fall in each category (i.e., southerly flow, northerly flow, and intense etesians).
The etesians typically blow northeasterly over the northern Aegean (Alexandroupoli, Skyros, and Mytilini) and northerly over the central Aegean (Naxos and Thira), and they are shifted northwesterly along the southsoutheastern Aegean coasts (Heraklion and Rhodes; Repapis et al. 1978). Note that the dominant etesian wind pattern is reproduced adequately. This is confirmed by the wind roses associated with the observed intense etesian days at nine stations over the Aegean Sea (not shown). Once the exceedances over the threshold $u$ are obtained, their distribution is inferred within the generalized Pareto family by estimating the model's parameters with the maximum likelihood approach (Martins and Stedinger 2000; Coles 2001). A visual check is then performed by using quantile-quantile plots $(\mathrm{Q}-\mathrm{Q}$ plot $)$. The generalized Pareto distribution (GPD) function for scale $=\sigma$ and shape $=\xi$ is given by

$$
G(x)=1-\left[1+\frac{\xi(x-u)}{\sigma}\right]^{-1 / \xi}
$$

for $1+\xi(x-u) / \sigma>0$ and $x>u$.

The shape parameter describes the tail behavior: bounded for negative values, exponential when $\xi=0$, heavy for positive values.

A wind turbine shall be designed to safely withstand the wind conditions, while the design values shall be clearly specified in the technical documentation. The wind regime for load and safety design considers the extreme wind conditions having a 50-yr recurrence period [International Electrotechnical Committee (IEC) 2005]. The $N$-yr wind speed is defined as the wind speed exceeded on average once in a period of $N$ years. Note that the length of the analyzed time series $(20 \mathrm{yr})$ can be considered sufficiently large to estimate the 50-yr return levels (Pryor et al. 2012). Therefore, we estimate the 50-yr return level RL at different hub heights $(50,80,100 \mathrm{~m})$ to define extreme etesians using the equation

$$
\mathrm{RL}=u+\frac{\sigma}{\xi}\left[\left(N n_{y} P_{u, n}\right)^{\xi}-1\right],
$$

where $n_{y}$ denotes the number of events per season and $P_{u, n}$ denotes the probability of being above the threshold $u$. In addition, the 2-, 5-, and 10-yr RL are estimated as 


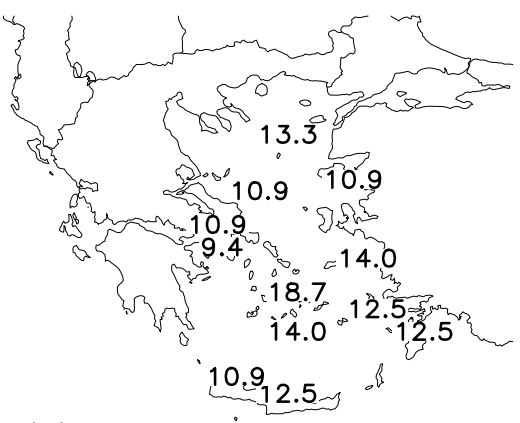

(a) OBS

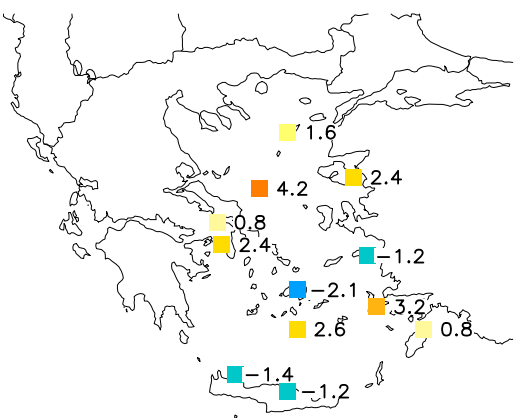

(d) DMI

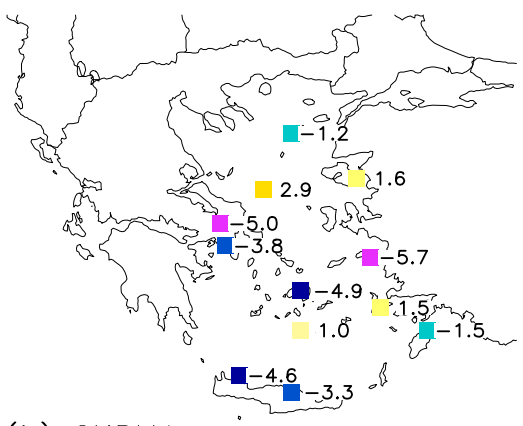

(b) CNRM 1

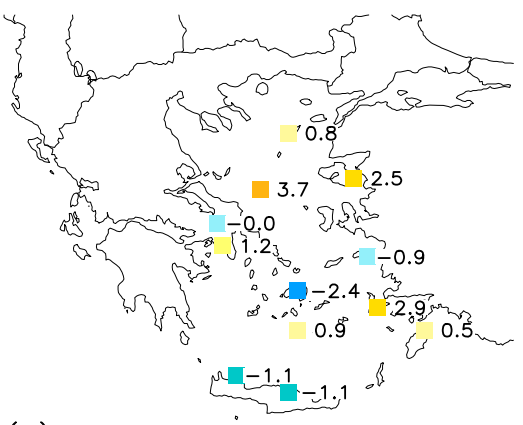

(e) SMHI

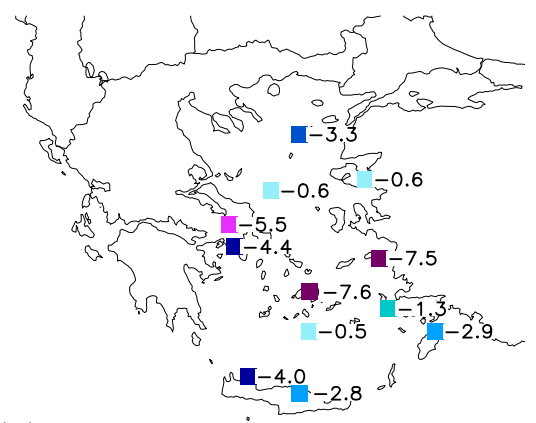

(c) CNRM2

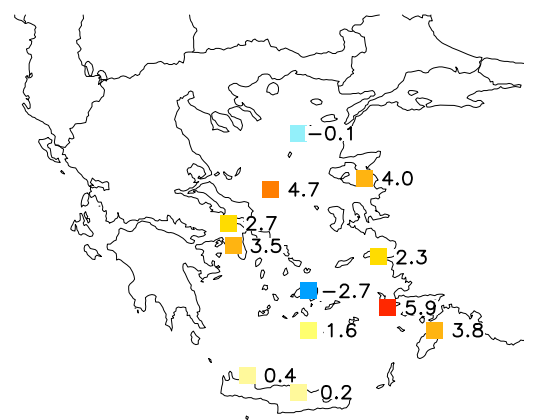

(f) IPSL

Hub Height 80-m Ref. Period: 1989-2008

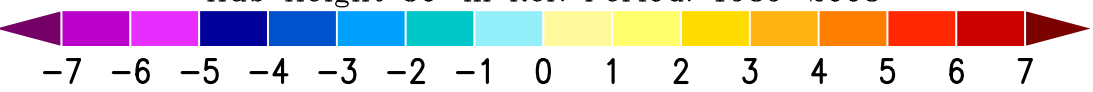

FIG. 2. (a) The observed estimated threshold values $\left(\mathrm{m} \mathrm{s}^{-1}\right)$ for the observational measurements. (b)-(f) Spatial distribution of the threshold biases (RCM - observations; $\mathrm{m} \mathrm{s}^{-1}$ ) at a hub height of $80 \mathrm{~m}$ for the EUR-11 simulations over the period 1989-2008.

well. This analysis quantifies the uncertainties in the RL estimates by using the profile likelihood approach (Coles 2001; Della-Marta et al. 2009).

Two important characteristics of any wind turbine are the nominal speed $v_{\text {nom }}$, which is the lowest wind speed at which a turbine operates at its rated capacity (i.e., at maximum power output) and the cutout speed $v_{\text {cutout }}$, which is the lowest wind speed at which there is risk for turbine damages (IEC 2005). Typical values are usually in the range of $12-16 \mathrm{~m} \mathrm{~s}^{-1}$ for the $v_{\text {nom }}$ and $20-35 \mathrm{~m} \mathrm{~s}^{-1}$ for the $v_{\text {cutout }}$. Current installed wind turbines in the Aegean have an average $v_{\text {nom }}$ and $v_{\text {cutout }}$ equal to 14 and $25 \mathrm{~m} \mathrm{~s}^{-1}$, respectively (http://www.en.energyregister.gr). Thus, these values are considered here, and their return period (RP) is estimated.

\section{Results}

Prior to the specific analysis on extremes, a brief description of the main wind characteristics based on the observational measurements at the 12 stations in the Aegean is given. The stations located in the central and western Aegean are characterized by mean annual wind speeds $\geq 7 \mathrm{~m} \mathrm{~s}^{-1}$ at $80 \mathrm{~m}$ (i.e., wind power class $\geq 3$; IEC 2005), which are generally considered suitable for wind power generation (Archer and Jacobson 2005). The highest values are found over the central Aegean Sea with annual wind speed of 10.8 and $8.7 \mathrm{~m} \mathrm{~s}^{-1}$ at Naxos and Thira, respectively. When only the intense etesians are considered, then all reporting stations experience mean wind speeds $\geq 11 \mathrm{~m} \mathrm{~s}^{-1}$ at $80 \mathrm{~m}$ (i.e., wind power class 1 ; IEC 2005). In the following subsections, as the analysis on all the selected hub heights shows similar findings, only results at $80 \mathrm{~m}$ are presented.

\section{a. GPD validation}

The results based on the RCMs suggest that in most cases (especially for the SMHI and IPSL models) the GPD fits are reasonably good except for a few sites; this is confirmed by the Q-Q plots (see the example of Naxos in online supplemental Figs. S1b-f). As for the observed values, the results suggest that extreme wind speeds are very well fitted by the GPD. The high quality of these fits suggests that reliable extreme wind climatology can be obtained. 


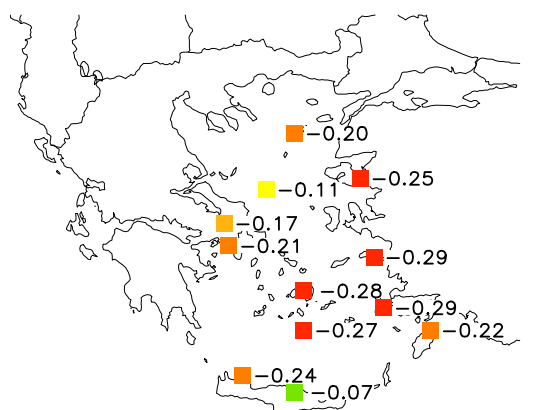

(a) OBS

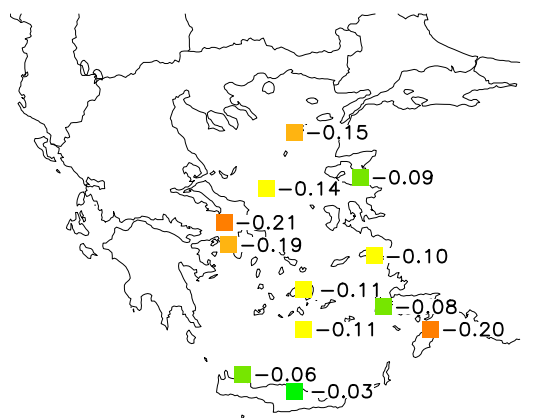

(d) DMI

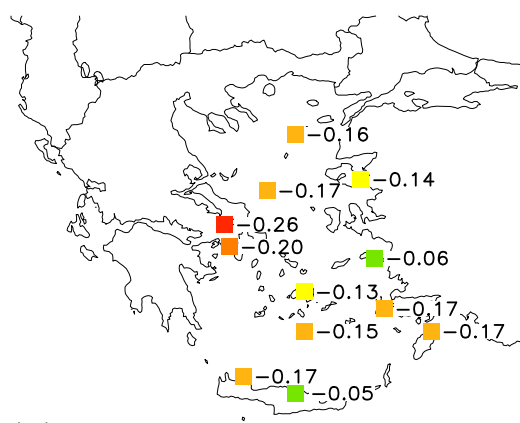

(b) CNRM 1

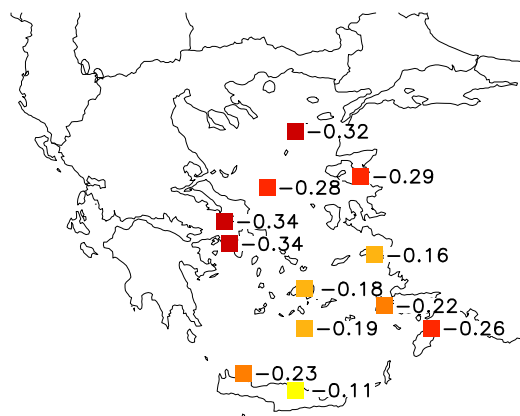

(e) SMHI

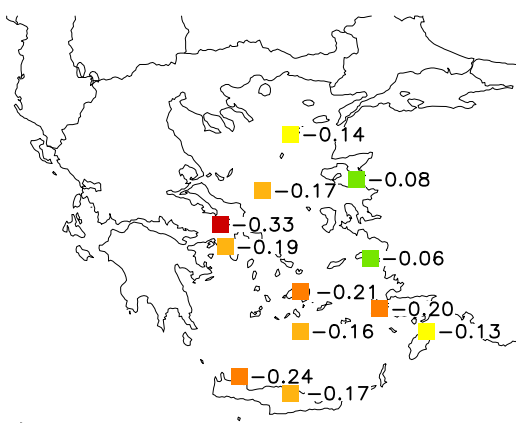

(c) CNRM2

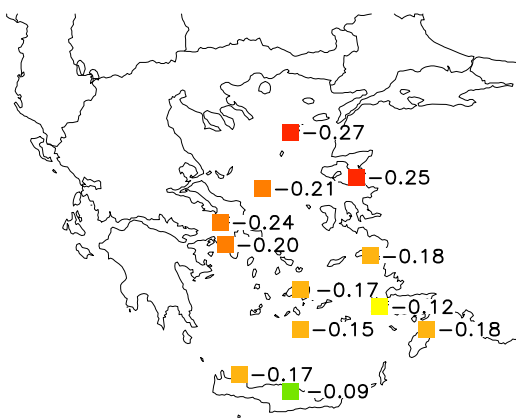

(f) IPSL

Hub Height 80-m Ref. Period: 1989-2008

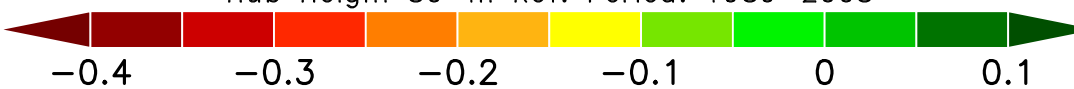

FIG. 3. Spatial distribution of the shape parameter $\xi$ at the hub height of $80 \mathrm{~m}$ for (a) the observational measurements and (b)-(f) the EUR-11 simulations over 1989-2008.

\section{b. GPD parameters at $80 \mathrm{~m}$}

The estimated biases (RCM - observation) of the threshold levels at hub height $80 \mathrm{~m}$ are displayed in Fig. 2. In all datasets higher thresholds are found at the central Aegean stations (Naxos and Thira), with values around $15 \mathrm{~m} \mathrm{~s}^{-1}$. Lower thresholds are visible in the western Aegean Sea (Elliniko, Tatoi, and Souda), which correspond to less etesian-exposed stations (Fig. 2). The DMI and SMHI models show better skill in reproducing the observed 90th percentile (Figs. 2d,e) than do the other three models. A clear underestimation of the thresholds, especially over the western and eastern parts of the etesian region, is found for CNRM1 and CNRM2 (Figs. 2b,c). The wind speed thresholds are overestimated by the IPSL model, especially over the western Aegean sites (Fig. 2f). Overall, most RCMs show good performance in simulating the threshold values and biases typically do not exceed 2-4 $\mathrm{m} \mathrm{s}^{-1}$ (Fig. 2).

Figure 3 presents the estimated shape parameter $\xi$ at $80 \mathrm{~m}$. The values are negative at all stations and hub heights (not shown for 50 and $100 \mathrm{~m}$ ). More specifically, values range between -0.03 and -0.35 implying bounded tails in the region, which is physically consistent with the constraint of the pressure gradient. RCM shape estimates are in fairly close agreement with the actual wind speed data.

As for the scale parameter $\sigma$ (Fig. 4), models show a homogeneous spatial behavior whereas observations (Fig. 4a) are characterized by higher spatial variability and higher values. The highest values of the scale parameter are identified for most of the RCMs (but CNRM2) in the northern and western parts of the domain (Fig. 4). In addition, the distribution of the scale parameter $\sigma$ seems to be inversely proportional to the threshold levels (unlike CNRM1 and CNRM2), indicating that sites with lower thresholds display wider distributions.

\section{c. Return levels}

In this section we analyze the spatial variability of 2-, 5-, 10-, and 50-yr RL at different hub heights (i.e., 50, 80 , and $100 \mathrm{~m}$ ). For wind turbine selection, the $50-\mathrm{yr}$ extreme wind is usually required (IEC 2005). Figure 5 shows the $50-\mathrm{yr}$ RL at $80 \mathrm{~m}$ (the results of the other heights are provided in the supplementary material). As in the previous figures, differences in wind exposure can be easily seen: the most etesian-exposed stations 


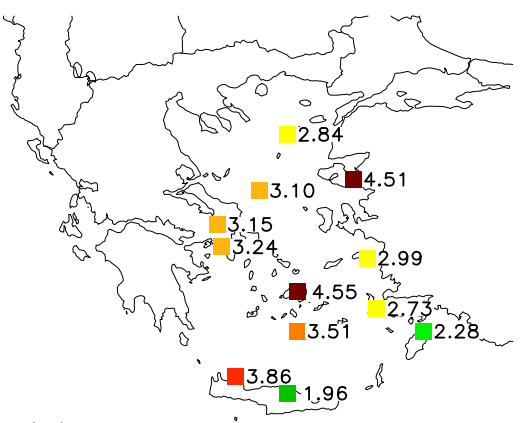

(a) OBS

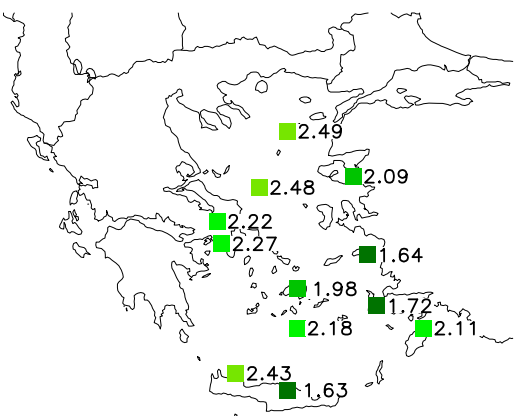

(d) DMI

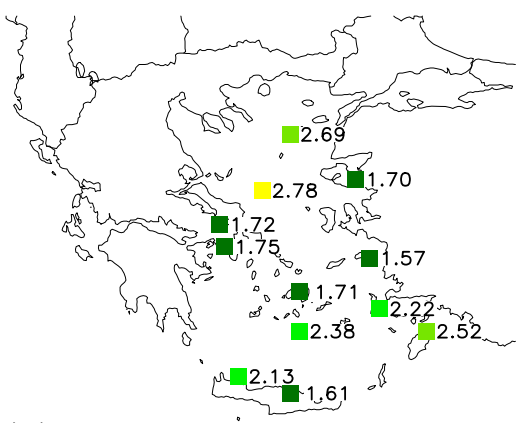

(b) CNRM 1

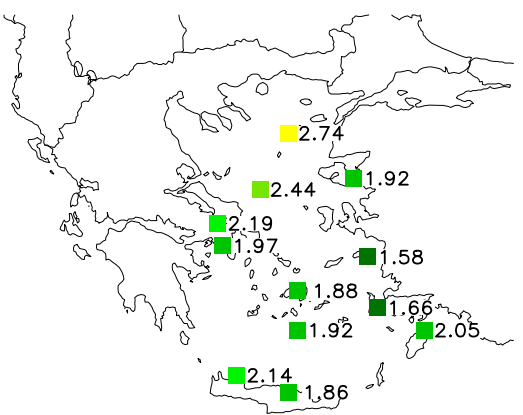

(e) SMHI

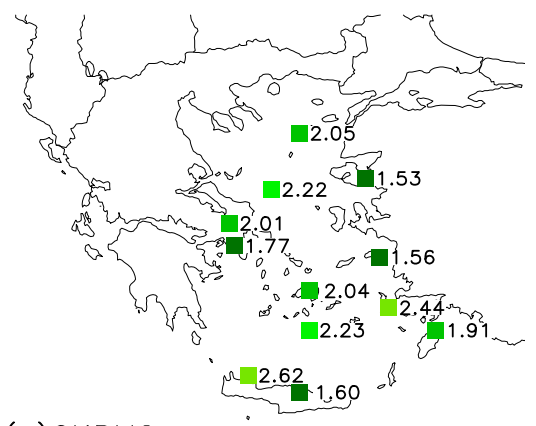

(c)CNRM2

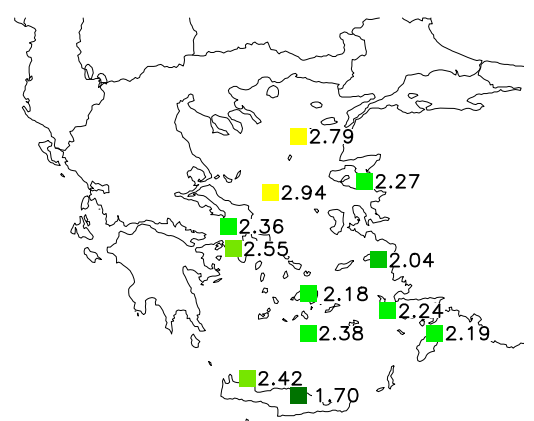

(f) IPSL

Hub Height 80-m Ref. Period: 1989-2008

\section{$\begin{array}{lllllllllll}1.5 & 1.8 & 2.1 & 2.4 & 2.7 & 3.0 & 3.3 & 3.6 & 3.9 & 4.2 & 4.5\end{array}$}

FIG. 4. As in Fig. 3, but for the scale parameter $\sigma$.

(i.e., exposed to the prevailing strongest winds, located mostly over north and central Aegean) exhibit the highest RL (Fig. 5). In comparison with RCMs, the 50 -yr RL of the observations has higher values (generally between 21 and $33 \mathrm{~m} \mathrm{~s}^{-1}$; Fig. 5a). As for the models, CNRM1 and CNRM2 tend to underestimate the wind extremes at most stations $(\sim 30 \%)$. Over the western Aegean Sea (Elliniko, Tatoi, and Souda), extremes are underestimated by models up to $50 \%$ (Figs. 5b,c). Dafka et al. (2018) have shown that the CNRM simulations tend to underestimate the mean wind speed $\left(3-5 \mathrm{~m} \mathrm{~s}^{-1}\right)$ over the Aegean Sea for the period 1989-2004 consistently with the underestimated pressure gradient over the Archipelago. They have also reported that this underestimation may indicate weaknesses in physical and land surface processes parameterization schemes. Wind speed RL is clearly underestimated in the SMHI model ( $\sim 18 \%$; Fig. $5 \mathrm{e})$. The DMI and IPSL models show good representation of the $\mathrm{RL}$ of the intense etesians wind speed, while biases over the Aegean do not exceed $\sim 9 \%-13 \%$ (Figs. 5d,f). The ability of regional models, such as the IPSL, to resolve major features of the topography and surface properties (such as coastal boundaries) as well as to develop accurate wind climatology has been also identified by previous studies (Dafka et al. 2018; Zhang et al. 2012; Salvação et al. 2014).

The 2-, 5-, and 10-yr RL for most of the stations over the Aegean Sea vary in the range of $20-30 \mathrm{~m} \mathrm{~s}^{-1}$ for the observational time series, 15 and $25 \mathrm{~m} \mathrm{~s}^{-1}$ for the DMI, SMHI, and IPSL models and 10 and $20 \mathrm{~m} \mathrm{~s}^{-1}$ for the CNRM1 and CNRM2 simulations (see supplemental Figs. S2-S4). Note that the underestimation of the RL increases with the RP; in particular, an RP of $50 \mathrm{yr}$ shows larger underestimation of around $3 \%-5 \%$ relative to the other RPs. The differences between the RL values at different hub heights are very small, around $1-2 \mathrm{~m} \mathrm{~s}^{-1}$ (from 50 to $80 \mathrm{~m}$ and from 80 to $100 \mathrm{~m}$ ) at all stations and RPs (not shown).

The characterization of the vulnerability of wind turbine and the evaluation of the risks associated with extreme winds is usually derived from a number of factors, including the frequency and intensity of the hazard. More specifically, cases that are characterized by lower thresholds but high RL, such as in Skyros and Thira (Fig. 2 and supplemental Fig. S6a), are considered to be associated with increased risk of turbine damage. Although Skyros has a low threshold of around $11 \mathrm{~m} \mathrm{~s}^{-1}$, a 


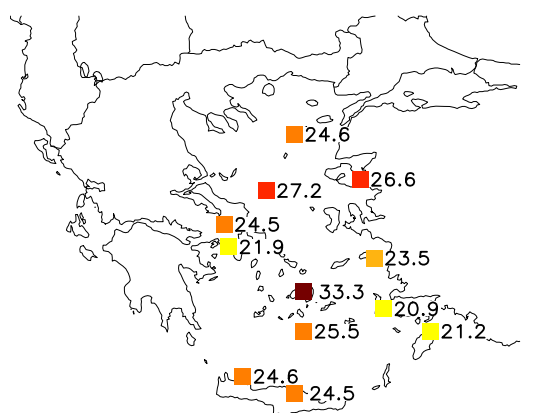

(a) OBS

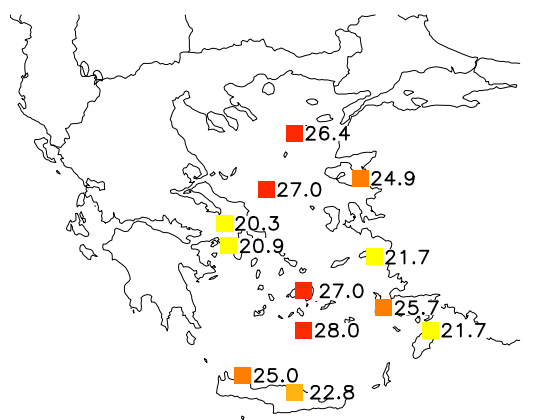

(d) DMI

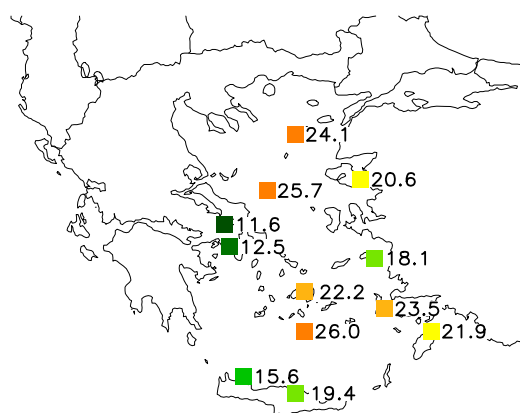

(b) CNRM 1

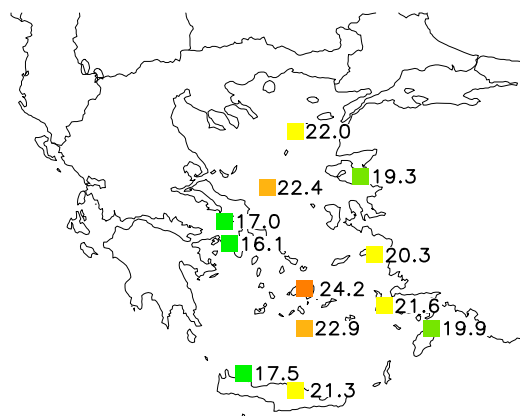

(e) SMHI

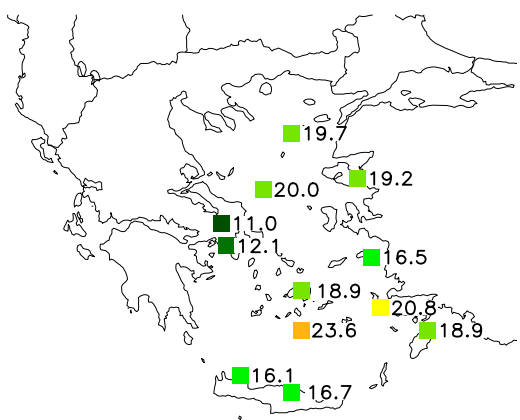

(c) CNRM2

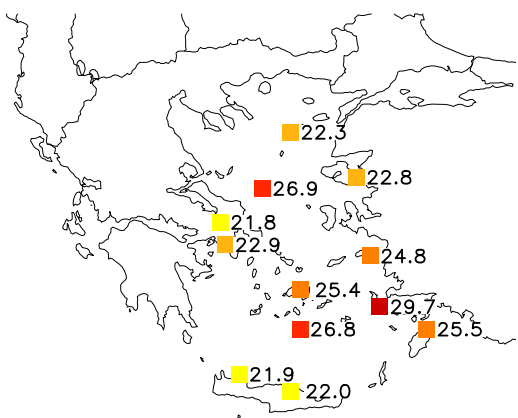

(f) IPSL

Hub Height 80-m Ref. Period: 1989-2008

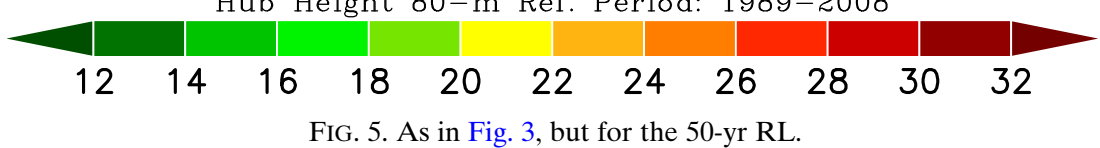

FIG. 5. As in Fig. 3, but for the 50-yr RL.

quite high 50-yr (2-yr) RL of 33 (24) $\mathrm{m} \mathrm{s}^{-1}$ is estimated. However, we should also emphasize that RL estimation is characterized by intrinsic uncertainties connected with the estimation of the shape parameters especially for longer RPs.

The uncertainty of the extreme wind speed is strongly related to the partial safety factor used in design. According to the IEC61400-1, this factor is based on the assumption that the uncertainty of the extreme wind speed is $10 \%$ (Ishihara and Yamaguchi 2015). The observations produce narrower confidence intervals, and thus, reduce the uncertainty in RL estimation for all RPs considered, over the central and eastern Aegean (see supplemental Fig. S5a). In comparing the 95\% confidence intervals resulting from models (see supplemental Figs. S5b-f) with observations, similar values can be seen in the SMHI (DMI) model in the central and eastern (northern and western) Aegean (for all RPs considered). Note that the uncertainty of the RL increases with the RP; in particular, an RP of $50 \mathrm{yr}$, which corresponds to a very extreme event, is associated with very large confidence intervals, and thus the RL should be interpreted with caution. Finally, the $95 \%$ confidence intervals at different hub heights show very small differences, around $0.1-0.2 \mathrm{~m} \mathrm{~s}^{-1}$ (from 50 to $80 \mathrm{~m}$ and 80 to $100 \mathrm{~m}$ ) at all stations and RPs (not shown).

Overall, the 50-yr extreme winds show some clear differences between the five simulations and the observational measurements (Fig. 5). For instance, the underestimation of the CNRM simulations with wind speed values approximately $5-7 \mathrm{~m} \mathrm{~s}^{-1}$ lower than the observed ones (Figs. 5b,c), especially over the western Aegean stations (Elliniko, Tatoi, and Souda). Despite these differences, some obvious common features between the RCMs and observations can be seen: the highest return wind speeds appear over the most etesian-exposed sites. Finally, the DMI and the IPSL models show the best performance regarding the 50-yr RL (Fig. 5d).

\section{d. Nominal and cutout speed}

The estimated RP in years (days) during which, at a given location, the wind speed exceeds the $v_{\text {cutout }}\left(v_{\text {nom }}\right)$ at $80 \mathrm{~m}$, is shown in Fig. 6 (supplemental Fig. S6). The wind-exposed stations (located over the central and northern Aegean Sea) can be identified because of the low $v_{\text {nom }}$ RPs (0-7 days; see supplemental Fig. S6). Simulated wind speeds of CNRM1 and CNRM2 exceed 


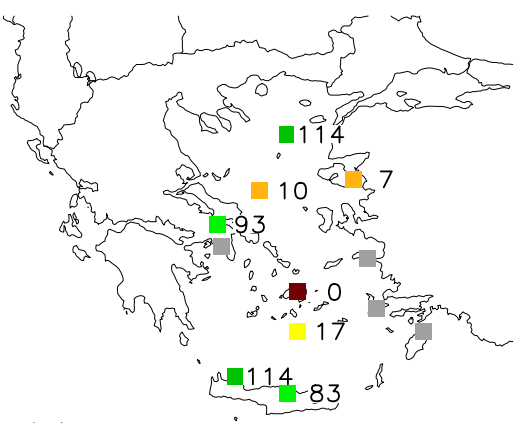

(a) OBS

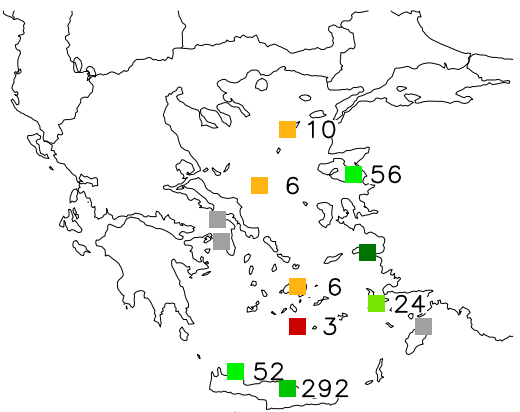

(d) DMI

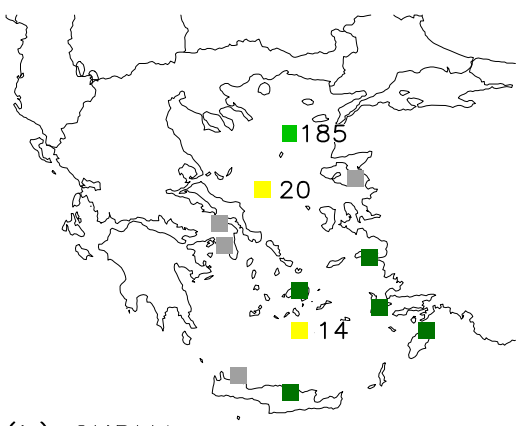

(b) CNRM 1

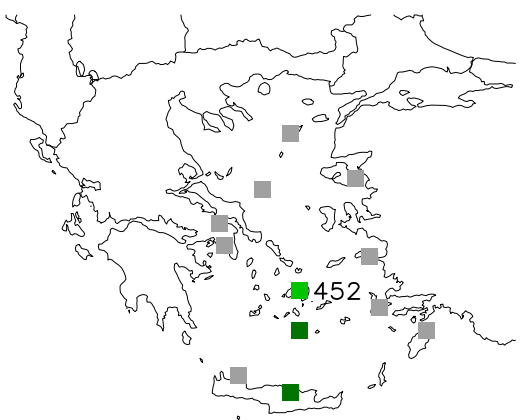

(e) SMHI

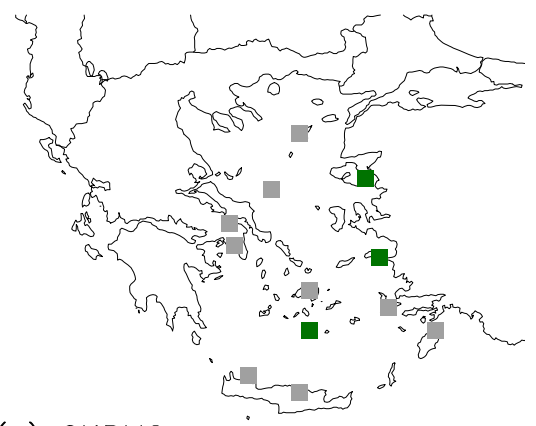

(c) CNRM2

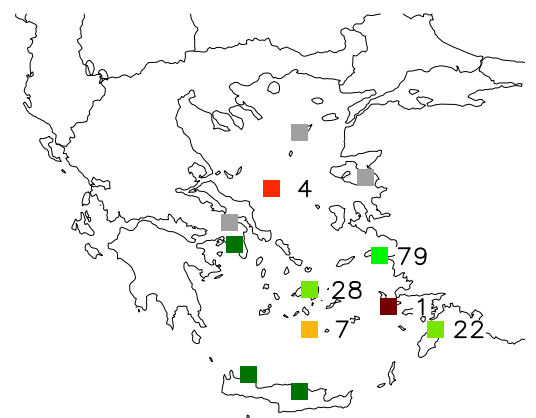

(f) IPSL

Hub Height 80-m Ref. Period: 1989-2008

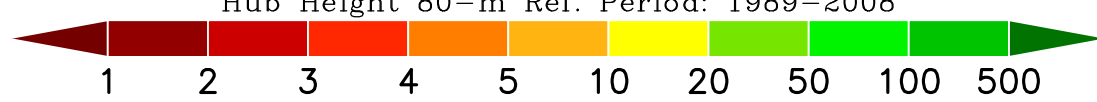

FIG. 6. Spatial distribution of the RPs in years during which the wind speed exceeds $v_{\text {cutout }}$ at a hub height of $80 \mathrm{~m}$ for 1989-2008. Gray squares indicate that the $v_{\text {cutout }}$ is beyond the upper bound of the distribution. Dark-green squares indicate an RP of $500+$ yr.

less frequently the $v_{\text {nom }}$ at most sites (except for the central Aegean Sea; see supplemental Figs. S6b,c) relative to the observed values (see supplemental Fig. S6a). In addition, there are no exceedances of the wind speed at rated power for Tatoi and Elliniko. As expected, the highest RPs (10-30 days) are found in regions that are less exposed to the etesian wind influence including the western Aegean sites. The distribution of $v_{\text {cutout }}$, which serves for safety and avoidance of turbine destruction, is very inhomogeneous, since the RPs range from $<2$ to $500+\mathrm{yr}$, as can be seen in Fig. 6. Since for many stations the distribution is bounded, in some cases the $v_{\text {cutout }}$ is beyond the upper bound (gray boxes, Fig. 6). For CNRM simulations, wind speed of $25 \mathrm{~m} \mathrm{~s}^{-1}$ is exceptional, with most RPs being higher than $100 \mathrm{yr}$. However, observational series from DMI and IPSL show that a few stations in the central Aegean basin feature relatively low RPs $[\sim(1-15)$ yr; Figs. 6a,d]. This finding potentially suggests that at these sites (especially in Naxos and Thira) wind turbines with higher or variable $v_{\text {cutout }}$ should be considered as more suitable for wind farm development. In addition, turbines with $v_{\text {nom }}$ and $v_{\text {cutout }}$ equal to 14 and $25 \mathrm{~m} \mathrm{~s}^{-1}$, respectively, are likely more suitable for wind farms development at the southeastern and northern Aegean sites (see Fig. 6 and supplemental Fig. S6a). Overall, the DMI model shows better skill in both estimates (i.e., $v_{\text {nom }}$ and $v_{\text {cutout }}$ ) when compared with observational measurements (Figs. 6a,d and supplemental Figs. S6a,d). The other RCMs show some limitations in this respect, especially the CNRM2, which shows a general underestimation almost everywhere of the $v_{\text {nom }}$ RPs (10-40 days; see supplemental Fig. S6c).

\section{Conclusions and outlook}

This study provided estimations of the 2-, 5-, 10-, and 50 -yr RL of intense etesians wind speed at 12 measuring stations in the Aegean (covering the period 1989-2008) and at three different hub heights by using an extreme value theory-based approach. The analysis used 6-hourly in situ measurements in comparison with model-simulated wind speeds from five RCMs, participating in the EURO-CORDEX initiative.

Results indicate that significant and substantial wind resources exist throughout the Aegean. Currently, the 
best operating conditions of wind turbines in the Aegean are defined by wind speed in the range $14-25 \mathrm{~ms}^{-1}$. According to these values, the most etesian-exposed stations (i.e., those lying in the central and northern Aegean) would be capable of operating approximately $90 \%$ at hub heights above $80 \mathrm{~m}$. However, there is a clear spatial dependence indicating a drop in the operating frequency (to roughly $25 \%$ ) at less etesianexposed stations. More specifically, the Aegean Sea can be divided into five distinct subregions (in decreasing order of RL) with regard to the highest RL in all RPs and hub heights: (i) central (Naxos, Thira), (ii) north (Lemnos and Skyros), (iii) east (Mytilini, Samos, and Kos), (iv) south (Herakleion and Rhodes), and (v) west (Tatoi, Elliniko, and Souda). The above subregions, which demonstrated high wind speeds and stable wind directions (specified by the typical etesian pattern), can potentially provide attractive prospects for future wind farms development.

In comparison with observational measurements, all models are able to reasonably reproduce the spatial distribution of the extremes at these specific stations in the Aegean. In line with previous studies, most RCM simulations slightly underestimate the extreme wind speeds for all RPs and hub heights. However, all models except one (CNRM) allow for a very good representation of wind extremes. Thus, these models can be considered a useful tool for impact assessment of wind extremes. Nevertheless, the identified large intermodel spread appears to be the largest source of uncertainty, and it might be linked to different representations of smaller-scale processes.

Overall, the central and northern Aegean areas are more prone to wind hazards than the others subregions; thus, medium-high-wind IEC class turbines can be more suitable. As for the turbine's design parameters, cutout wind speed $>25 \mathrm{~m} \mathrm{~s}^{-1}$ are recommended for the central Aegean. It is worth mentioning that this analysis is limited to the etesian winds (which are a summer phenomenon), and additional analyses for wind extremes during the winter period should be considered in a comprehensive energy potential assessment. However, this study provides a helpful assessment that could contribute to the planning of local wind farms.

Additional work considering the strengths and the weaknesses of various bias correction strategies to improve the models' performance has been already planned. Further analysis will provide new evidence on projected, bias-corrected extreme winds (e.g., Ivanov et al. 2018) for the twenty-first century, with the aim to address the potential for wind energy over the Aegean Archipelago.
Acknowledgments. The authors thank Dr. Michel Deque and Dr. Clotilde Dubois (CNRM), Dr. Grigory Nikulin (SMHI), and Dr. Fredrik Boberg (DMI) as well as Dr. Robert Vautard and Dr. Isabelle Tobin (IPSL) for providing the ALADIN-v5.3, ARPEGE-v5.2, RCA-v4, HIRHAM-v5, and WRF3.3.1 simulations, respectively. We are indebted to the Hellenic National Meteorological Service for the observational dataset. We are grateful to the anonymous reviewers for their constructive comments and suggestions, which improved the manuscript. The research leading to these results has received funding from the Greek State Scholarships Foundation and the DFG (German Science Foundation) project "The Etesian wind system and energy potential over the Aegean Sea; past, present, future."

\section{REFERENCES}

Anagnostopoulou, C., P. Zanis, E. Katragkou, I. Tegoulias, and K. Tolika, 2014: Recent past and future patterns of the etesian winds based on regional scale climate model simulations. Climate Dyn., 42, 1819-1836, https://doi.org/10.1007/s00382-013-1936-0.

Archer, C. L., and M. Z. Jacobson, 2005: Evaluation of global wind power. J. Geophys. Res., 110, D12110, https://doi.org/10.1029/ 2004JD005462.

Arya, S. P., 2001: Introduction to Micrometeorology. Academic Press, $420 \mathrm{pp}$.

Bagiorgas, H. S., G. Mihalakakou, S. Rehman, and L. M. Al-Hadhrami, 2012: Offshore wind speed and wind power characteristics for ten locations in Aegean and Ionian Seas. J. Earth Syst. Sci., 121, 975-987, https://doi.org/10.1007/ s12040-012-0203-9.

Balkema, A. A., and L. de Haan, 1974: Residual life time at great age. Ann. Probab., 2, 792-804, https://doi.org/10.1214/aop/ 1176996548.

Bloom, A., V. Kotroni, and K. Lagouvardos, 2008: Climate change impact of wind energy availability in the eastern Mediterranean using the regional climate model PRECIS. Nat. Hazards Earth Syst. Sci., 8, 1249-1257, https://doi.org/ 10.5194/nhess-8-1249-2008.

Borhan, Y., 1998: Mesoscale interactions on wind energy potential in the northern Aegean region: A case study. Renewable Sustainable Energy Rev., 2, 353-360, https://doi.org/10.1016/ S1364-0321(98)00006-9.

Coles, S., 2001: An Introduction to Statistical Modeling of Extreme Values. Springer, 208 pp.

Dafka, S., E. Xoplaki, A. Toreti, P. Zanis, E. Tyrlis, C. Zerefos, and L. Luterbacher, 2016: The etesians: From observations to reanalysis. Climate Dyn., 47, 1569-1585, https://doi.org/10.1007/ s00382-015-2920-7.

- A. Toreti, J. Luterbacher, P. Zanis, E. Tyrlis, and E. Xoplaki, 2018: On the ability of RCMs to capture the circulation pattern of etesians. Climate Dyn., https://doi.org/10.1007/s00382017-3977-2, in press.

Davison, A. C., and R. L. Smith, 1990: Models for exceedances over high thresholds (with discussion). J. Roy. Stat. Soc., 52B, 237-254.

Dee, D. P., and Coauthors, 2011: The ERA-Interim reanalysis: Configuration and performance of the data assimilation system. 
Quart. J. Roy. Meteor. Soc., 137, 553-597, https://doi.org/ 10.1002/qj.828.

Della-Marta, P. M., H. Mathis, C. Frei, M. A. Liniger, J. Kleinn, and C. Appenzeller, 2009: The return period of wind storms over Europe. Int. J. Climatol., 29, 437-459, https://doi.org/ 10.1002/joc. 1794

de Oliveira, M. M., N. F. Ebecken, J. L. de Oliveira, and E. Gilleland, 2011: Generalized extreme wind speed distributions in South America over the Atlantic Ocean region. Theor. Appl. Climatol., 104, 377-385, https://doi.org/10.1007/ s00704-010-0350-3.

Emeis, S., 2005: How well does a power law fit to a diabatic boundary-layer wind profile? DEWI Mag., 26, 59-62.

Ernst, B., and J. R. Seume, 2012: Investigation of site-specific wind field parameters and their effect on loads of offshore wind turbines. Energies, 5, 3835-3855, https://doi.org/10.3390/ en5103835.

Fyrippis, I., P. J. Axaopoulos, and G. Panayiotou, 2010: Wind energy potential assessment in Naxos Island, Greece. Appl. Energy, 87, 577-586, https://doi.org/10.1016/ j.apenergy.2009.05.031.

Hueging, H., R. Haas, K. Born, D. Jacob, and J. G. Pinto, 2013: Regional changes in wind energy potential over Europe using regional climate model ensemble projections. J. Appl. Meteor. Climatol., 52, 903-917, https://doi.org/ 10.1175/JAMC-D-12-086.1.

IEC, 2005: Design requirements. Part 1, Wind turbines, International Standard IEC 61400-1, 3rd ed. International Electrotechnical Commission, Geneva, Switzerland, 11 pp., https://www.saiglobal.com/pdftemp/previews/osh/iec/iec61000/ 61400/iec61400-1\%7Bed3.0\%7Den.pdf.

Ishihara, T., and A. Yamaguchi, 2015: Prediction of the extreme wind speed in the mixed climate region by using Monte Carlo simulation and measure-correlate-predict method, Wind Energy, 18, 171-186, https://doi.org/10.1002/we.1693.

Ivanov, M. A., J. Luterbacher, and S. Kotlarski, 2018: Climate model biases and modification of the climate change signal by intensity dependent bias correction. J. Climate, https://doi.org/ 10.1175-JCLI-D-17-0765.1, in press.

Jacob, D., and Coauthors, 2014: EURO-CORDEX: New highresolution climate change projections for European impact research. Reg. Environ. Change, 14, 563-578, https://doi.org/ 10.1007/s10113-013-0499-2; Corrigendum, https://doi.org/ 10.1007/s10113-014-0587-y.

Kislov, A., and T. Matveeva, 2016: An extreme value analysis of wind speed over the European and Siberian parts of Arctic region. Atmos. Climate Sci., 6, 205-223, https://doi.org/ 10.4236/acs.2016.62018.

Kostopoulos V., C. Helmis, and I. Raptis, 2013: Experimental study of the turbulent structure of the surface marine atmospheric boundary layer over the Aegean pelagos under etesian winds. Advances in Meteorology, Climatology and Atmospheric Physics, 1063-1068, Springer, https://doi.org/ 10.1007/978-3-642-29172-2_148.

Kubik, M. L., P. J. Coker, and C. Hunt, 2011: Using meteorological wind data to estimate turbine generation output: A sensitivity analysis. Proc. World Renewable Energy Congress, Linköping, Sweden, World Renewable Energy Network, 4074-4081, http://www.ep.liu.se/ecp/057/vol15/004/ ecp57vol15_004.pdf.

Kunz, M., S. Mohr, M. Rauthe, R. Lux, and C. Kottmeier, 2010: Assessment of extreme wind speeds from regional climate models-Part 1: Estimation of return values and their evaluation. Nat. Hazards Earth Syst. Sci., 10, 907-922, https://doi.org/10.5194/nhess-10-907-2010.

Martins, E. S., and J. R. Stedinger, 2000: Generalized maximum likelihood GEV quantile estimators for hydrologic data. Water Resour. Res., 36, 737-744, https://doi.org/10.1029/ 1999WR900330.

Mölders, N., D. Khordakova, S. Gende, and G. Kramm, 2015: Uncertainty of wind power usage in complex terrain-A case study. Atmos. Climate Sci., 5, 228-244, https://dx.doi.org/ 10.4236/acs.2015.53017.

Newman, J. F., and P. M. Klein, 2014: The impacts of atmospheric stability on the accuracy of wind speed extrapolation methods. Resources, 3, 81-105, https://doi.org/10.3390/ resources3010081.

Ng, C., and L. Ran, 2016: Offshore Wind Farms: Technologies, Design and Operation. Woodhead Publishing, $654 \mathrm{pp}$.

Outten, S. D., and I. Esau, 2013: Extreme winds over Europe in the ENSEMBLES regional climate models. Atmos. Chem. Phys., 13, 5163-5172, https://doi.org/ 10.5194/acp-13-5163-2013.

Owen, R., 2004: Lake Michigan offshore wind resource assessment. Wisconsin Focus on Energy Final Rep., 67 pp., http:// wiwindinfo.com/data/lakemichiganwindresource_finalreport.pdf.

Patlakas, P., G. Galanis, N. Barranger, and G. Kallos, 2016: Extreme wind events in a complex maritime environment: Ways of quantification. Wind Eng. Ind. Aerodyn., 149, 89-101, https://doi.org/10.1016/j.jweia.2015.11.006.

Pickands, J., 1975: Statistical inference using extreme order statistics. Ann. Stat., 3, 119-131, https://doi.org/10.1214/aos/1176343003.

Pineda, I., and P. Tardieu, Eds., 2018: Wind in power 2017: Annual combined onshore and offshore wind energy statistics. WindEurope Rep., 25 pp., https://windeurope.org/wp-content/ uploads/files/about-wind/statistics/WindEurope-AnnualStatistics-2017.pdf.

Prein, A. F., and Coauthors, 2016: Precipitation in the EUROCORDEX $0.11^{\circ}$ and $0.44^{\circ}$ simulations: High resolution, high benefits? Climate Dyn., 46, 383-412, https://doi.org/10.1007/ s00382-015-2589-y.

Pryor, S. C., R. J. Barthelmie, N. E. Clausen, M. Drews, N. MacKellar, and E. Kjellström, 2012: Analyses of possible changes in intense and extreme wind speeds over northern Europe under climate change scenarios. Climate Dyn., 38, 189-208, https://doi.org/10.1007/s00382-010-0955-3.

Ray, M. L., A. L. Rogers, and J. G. McGowan, 2006: Analysis of wind shear models and trends in different terrain. Proc. American Wind Energy Association Windpower Conf., Pittsburg, PA, American Wind Energy Association, 14 pp., http://citeseerx.ist.psu.edu/ viewdoc/download?doi=10.1.1.574.7468\&rep=rep1\&type =pdf.

Rehman, S., L. M. Al-Hadhrami, M. Mahbub Alam, and J. P. Meyer, 2013: Empirical correlation between hub height and local wind shear exponent for different sizes of wind turbines. Sustainable Energy Technol. Assess., 4, 45-51, https:// doi.org/10.1016/j.seta.2013.09.003.

Repapis, C., C. Zerefos, and B. Tritakis, 1978: On the etesians over the Aegean. Proc. Acad. Athens, 52, 572-606.

Salvação, N., M. Bernardino, and C. Guedes Soares, 2014: Assessing mesoscale wind simulations in different environments. Comput. Geosci., 71, 28-36, https://doi.org/10.1016/ j.cageo.2014.04.017.

Tobin, I., and Coauthors, 2016: Climate change impacts on the power generation potential of a European mid-century wind farms scenario. Environ. Res. Lett., 11, 034013, https://doi.org/ 10.1088/1748-9326/11/3/034013. 
Tombrou, M., and Coauthors, 2015: Physical and chemical processes of air masses in the Aegean Sea during etesians: AegeanGAME airborne campaign. Sci. Total Environ., 506-507, 201-216, https://doi.org/10.1016/j.scitotenv.2014.10.098.

Tyrlis, E., and J. Lelieveld, 2013: Climatology and dynamics of the summer etesian winds over the eastern Mediterranean. J. Atmos. Sci., 70, 3374-3396, https://doi.org/ 10.1175/JAS-D-13-035.1.
Vagenas, C., C. Anagnostopoulou, and K. Tolika, 2017: Climatic study of the marine surface wind field over the Greek seas with the use of a high resolution RCM focusing on extreme winds. Climate, 5, 29, https://doi.org/10.3390/cli5020029.

Zhang, C., Y. Wang, A. Lauer, and K. Hamilton, 2012: Configuration and evaluation of the WRF Model for the study of Hawaiian regional climate. Mon Wea. Rev., 140, 3259-3277, https://doi.org/10.1175/MWR-D-11-00260.1. 